\title{
Nanotechnology Enabled Hybrid Power System \\ Suitable for Portable Telecommunications and Sensor Applications
}

Rebecca G. Willmott, Kurt Eisenbeiser,
Carl A. Picconatto, and James C. Ellenbogen

Rebecca G. Willmott, Kurt Eisenbeiser,
Carl A. Picconatto, and James C. Ellenbogen

\section{MITRE

Rebecca G. Willmott, Kurt Eisenbeiser,
Carl A. Picconatto, and James C. Ellenbogen

McLean, Virginia

\author{
December 2010
MP100372 \\ December 2010
MP100372 \\ December 2010
MP100372
}

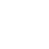

(n)

ed Hybrid Power System 


\section{Report Documentation Page}

Public reporting burden for the collection of information is estimated to average 1 hour per response, including the time for reviewing instructions, searching existing data sources, gathering and maintaining the data needed, and completing and reviewing the collection of information. Send comments regarding this burden estimate or any other aspect of this collection of information,

including suggestions for reducing this burden, to Washington Headquarters Services, Directorate for Information Operations and Reports, 1215 Jefferson Davis Highway, Suite 1204, Arlington

VA 22202-4302. Respondents should be aware that notwithstanding any other provision of law, no person shall be subject to a penalty for failing to comply with a collection of information if it

does not display a currently valid OMB control number.

\begin{tabular}{|c|c|c|}
\hline $\begin{array}{l}\text { 1. REPORT DATE } \\
\text { DEC } \mathbf{2 0 1 0}\end{array}$ & 2. REPORT TYPE & $\begin{array}{l}\text { 3. DATES COVERED } \\
\mathbf{0 0 - 0 0 - 2 0 1 0} \text { to } \mathbf{0 0 - 0 0 - 2 0 1 0}\end{array}$ \\
\hline \multirow{3}{*}{\multicolumn{2}{|c|}{$\begin{array}{l}\text { 4. TITLE AND SUBTITLE } \\
\text { Nanotechnology Enabled Hybrid Power System Suitable for Portable } \\
\text { Telecommunications and Sensor Applications }\end{array}$}} & 5a. CONTRACT NUMBER \\
\hline & & 5b. GRANT NUMBER \\
\hline & & 5c. PROGRAM ELEMENT NUMBER \\
\hline \multirow{3}{*}{\multicolumn{2}{|c|}{ 6. AUTHOR(S) }} & 5d. PROJECT NUMBER \\
\hline & & 5e. TASK NUMBER \\
\hline & & 5f. WORK UNIT NUMBER \\
\hline \multicolumn{2}{|c|}{$\begin{array}{l}\text { 7. PERFORMING ORGANIZATION NAME(S) AND ADDRESS(ES) } \\
\text { MITRE Corporation,7525 Colshire Drive,McLean,VA,22102 }\end{array}$} & $\begin{array}{l}\text { 8. PERFORMING ORGANIZATION } \\
\text { REPORT NUMBER }\end{array}$ \\
\hline \multirow{2}{*}{\multicolumn{2}{|c|}{ 9. SPONSORING/MONITORING AGENCY NAME(S) AND ADDRESS(ES) }} & 10. SPONSOR/MONITOR'S ACRONYM(S) \\
\hline & & $\begin{array}{l}\text { 11. SPONSOR/MONITOR'S REPORT } \\
\text { NUMBER(S) }\end{array}$ \\
\hline
\end{tabular}

12. DISTRIBUTION/AVAILABILITY STATEMENT

Approved for public release; distribution unlimited

13. SUPPLEMENTARY NOTES

14. ABSTRACT

A prototype nanotechnology-enabled hybrid power system has been developed and tested in the laboratory. The system, which consists of a nanotechnology-based battery and supercapacitor plus a dynamic power management circuit, has been designed to meet the power needs of high power, low duty cycle applications, such as telecommunications equipment or unattended ground sensors. The hybrid system has almost 17 times the specific energy of the supercapacitor alone and 3 times the specific power of the battery alone. Under load conditions similar to those found in a telecommunications system, the nanotechnology-enabled hybrid power system has 34 per cent more capacity than the battery alone and 30 per cent more capacity than the combined capacities of the battery and supercapacitor taken together.

15. SUBJECT TERMS

16. SECURITY CLASSIFICATION OF:

a. REPORT unclassified b. ABSTRACT unclassified c. THIS PAGE unclassified
17. LIMITATION OF ABSTRACT

Same as Report (SAR)
18. NUMBER 19a. NAME OF OF PAGES RESPONSIBLE PERSON

26 



\section{Nanotechnology Enabled Hybrid Power System Suitable for Portable Telecommunications and Sensor Applications}

Rebecca G. Willmott, Kurt Eisenbeiser,

December 2010

Carl A. Picconatto, and James C. Ellenbogen

MP100372

Sponsors: U.S. Government NanoEnabled Technology Initiative and The MITRE Corporation

Project Nos. 15105320 and 20MSR053

Dept. E552

Approved for public release;

distribution unlimited.

Release Case No. 11-0419

Copyright () 2010 by The MITRE Corporation. All rights reserved. 



\begin{abstract}
A prototype nanotechnology-enabled hybrid power system has been developed and tested in the laboratory. The system, which consists of a nanotechnology-based battery and supercapacitor, plus a dynamic power management circuit, has been designed to meet the power needs of high power, low duty cycle applications, such as telecommunications equipment or unattended ground sensors. The hybrid system has almost 17 times the specific energy of the supercapacitor alone and 3 times the specific power of the battery alone. Under load conditions similar to those found in a telecommunications system, the nanotechnology-enabled hybrid power system has 34 per cent more capacity than the battery alone and 30 per cent more capacity than the combined capacities of the battery and supercapacitor taken together.
\end{abstract}





\subsection{Introduction}

Batteries are common energy storage devices that are very efficient at supplying power for applications with constant power demands. However, applications such as portable telecommunications equipment and unattended ground sensors (UGS) present particularly challenging problems for batteries. Both of these applications require high energy density storage to provide long lifetimes, while also requiring high power capability to meet the high current draw required to send data over a wireless link. Such a load profile, with high power pulses interposed onto a steady background power load, is difficult to match efficiently with today's batteries. The best secondary batteries available today, Li-ion, operate efficiently at low power levels. However, as the power levels in Li-ion batteries increase above $1 \mathrm{C}$ (i.e., the discharge rate that will drain the full capacity of the battery in one hour), battery efficiency drops and capacity is lost as heat. The capacity of a typical Li-ion battery decreases by 50 per cent as the discharge rate increases from $1 \mathrm{C}$ to $5 \mathrm{C}$ (i.e., the rate that will drain the full capacity of the battery in 1/5 hour). In addition, high discharge rates can cause permanent capacity loss or failure in Li-ion batteries.

To prevent the inefficiency and capacity loss associated with operation at high discharge rates, most battery systems are sized to meet the peak power demands of the application and prevent excessive discharge rates. For applications with low duty cycles, this leads to battery sizes that are significantly larger than ideal, thereby increasing the size and weight of the system. To address this issue, battery manufacturers have been developing and manufacturing high-rate batteries. Several approaches have been taken, such as modifications to the cathode material [1] or nanostructured anodes [2]. To date, however, many of these attempts to improve the power performance of the battery have resulted in significant degradation in the energy density of the cell. This translates to decreased capacity for a battery of fixed size, which again leads to increased size and weight for the system.

One approach that has shown promise to address these issues for low duty cycle applications is the hybrid power system. Figure 1 shows on a Ragone plot the performance of various energy storage technologies. By combining multiple technologies in a hybrid system, the operational space of the system can be increased over what is possible with any of the individual technologies. One of the hybrid power systems that has been demonstrated is a system that combines batteries and capacitors $[3,4]$. These hybrid systems have shown improved performance both in portable electronics systems [5] and in electric vehicles [6,7].

As seen in Figure 1, capacitors have significantly higher specific power than batteries, but also much lower specific energy. Thus, in the hybrid approach the capacitor supplies power during the high current spikes in the load profile, while the battery is used to supply power during the baseline load phase, as well as to recharge the capacitor. Since the capacitor acts as a buffer between the load and the battery, high power spikes are less likely to reach the battery. In this system, the battery can be right-sized to meet the overall energy demands of the application without danger of battery damage or low efficiency performance. Similarly the capacitor can be 


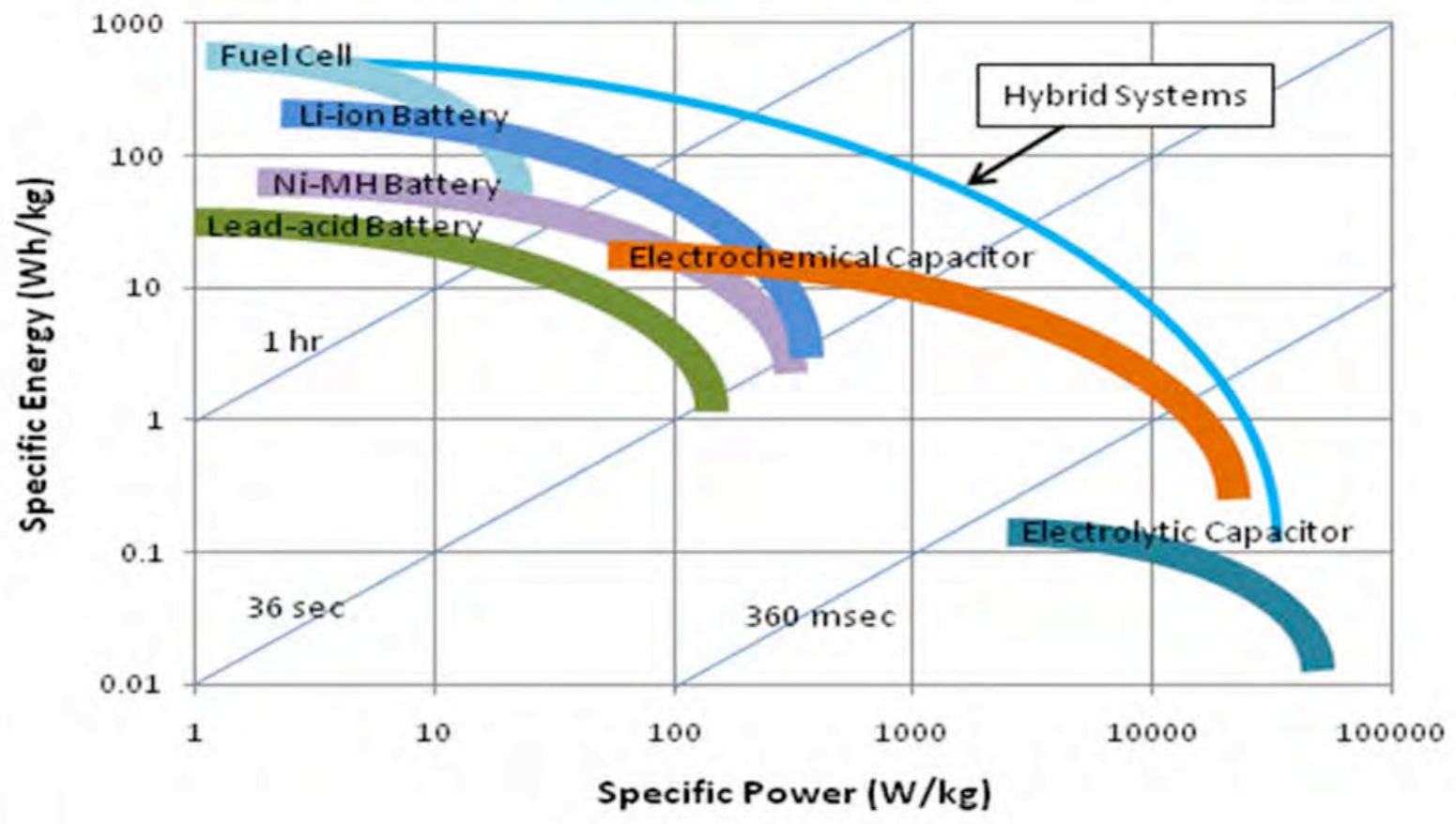

Figure 1. Ragone plot showing relative performance of various energy storage technologies. 
sized to meet the high power demands of the system, and this approach can reduce greatly the overall size and weight of a power system.

Application of nanotechnology also is having significant impact in the power research community and in industry for reducing the size and weight of portable power systems. Nanotechnology had its practical origins in the 1980s and embraces the science and engineering of understanding and manipulating materials on scales less than $100 \mathrm{~nm}$. Over the past decade, it has led to important advances in fields as diverse as electronics and medicine. However, it has had particularly dramatic benefits for the development of materials systems structured on the nanometer scale to improve energy storage devices of the type involved in the hybrid portable power systems of interest here.

Batteries have benefited from the higher surface area possible with nanostructured materials. One example is the Toshiba Super Charge Battery [2]. This battery uses a nanoparticle-based anode, with increased surface area, to improve lithium ion intercalation and prevent electrolyte reduction under high charge rate conditions. Similarly, A123 Systems has developed a battery using a nanoparticle-based cathode [8]. The nanoparticles are coated with a highly conductive layer to reduce internal resistance and improve the discharge rate.

Nanotechnology also has been used to improve capacitors [9]. The capacity of a capacitor is directly related to the charge storage surface area in the device and inversely related to the separation between opposite charge storage surfaces. Nanotechnology is perfectly suited to both increase the surface area in a given volume and to reduce and control the separation between structures down to very small dimensions. One example of this is the use of nanostructured activated carbon $[10,11]$ or onion-like carbon nanoparticles [12] to increase greatly the electrode surface area and thus the energy and power density in electrochemical capacitors. Similar nanostructures have been used to improve electrostatic capacitors. For example, metal-insulatormetal capacitor arrays fabricated in anodic aluminum nanoporous templates have achieved high capacitance per unit planar area [13].

In this paper, we describe applied research we have done that leverages nanotechnology-enabled commercial batteries and supercapacitors in a hybrid power system in order to demonstrate improved system performance. This system combines a nanoenabled Li-ion battery with a nanotechnology-enhanced supercapacitor, plus a dynamic power management circuit. It exhibits performance, in terms of capacity under load, that is better than either the battery or the capacitor alone, and also better than the sum of the performances exhibited by these two components. 



\subsection{System Overview}

A schematic of the Nanotechnology-enabled Hybrid Power System (NHPS) we have developed appears in Figure 2. The system consists of three elements. The high-energy storage component is responsible for meeting the long term energy needs of the application to which it is connected. The key requirement considered in choosing this component is that it have high energy density in the size range of interest (approximately $54 \mathrm{in}^{3}$, similar to the size of common military batteries BA5590 and UBI-2590). It also must be rechargeable so that it can be reused multiple times, require little maintenance, operate over a wide temperature range, and be available commercially. A battery from A123 Systems, shown in Figure 3, met all these requirements and was chosen for this prototyping effort.

A123 Systems uses nanotechnology-based innovations to produce Li-ion batteries with some of the highest discharge rates available commercially. The principal difference between the A123 cells and conventional Li-ion cells is the cathode material. Lithium iron phosphate $\left(\mathrm{LiFePO}_{4}\right)$ is a cathode material with many desirable characteristics: low cost, good thermal stability, and high capacity. However, its low electronic conductivity limited early adoption. A123's cells use nanoparticles of $\mathrm{LiFePO}_{4}$, coated with conductive materials. The high surface area of the nanoparticles allows excellent interpenetration of the conductive materials to produce a high electronic conductivity in the cathode. This high conductivity leads to cells capable of a very high discharge rate. A123's cells can be continuously discharged at rates up to $30 \mathrm{C}$, with peak rates up to $100 \mathrm{C}$, and have specific energies up to $109 \mathrm{Wh} / \mathrm{kg}$.

The high-power delivery component in the NHPS is responsible for meeting the instantaneous power needs of the application. This component must be chosen so that its power rating exceeds the peak power demand from the application and its capacity can meet the energy requirements of the system over short times. The high power component also needs to have a very long lifetime and a wide temperature operating window. For our purposes, we also required that it be commercially available. With these requirements in mind, a supercapacitor manufactured by Ioxus, shown in Figure 4, was chosen.

As is the case for the battery discussed above, the Ioxus supercapacitors all use nanotechnologybased innovations to achieve capacity much higher than is possible for conventional capacitors. The Ioxus supercapacitors are electrochemical double layer capacitors (EDLCs), where instead of using a conventional dielectric to separate the charge, an electrical double layer is established to maintain charge separation. The effective separation of this layer can be much thinner than that in conventional dielectrics, resulting in very high capacitances. The capacity of the Ioxus supercapacitors is increased further through the use of nanoporous activated carbon as the charge storage medium. The high surface to volume ratio enabled by this nanostructured material allows a very large amount of charge to be stored in a small volume, resulting in very high capacitance in these devices. The high capacitance, in turn, results in very high specific power. Ioxus supercapacitors can provide power levels up to $20,000 \mathrm{~W} / \mathrm{kg}$, with an associated specific energy up to $5 \mathrm{Wh} / \mathrm{kg}$. 


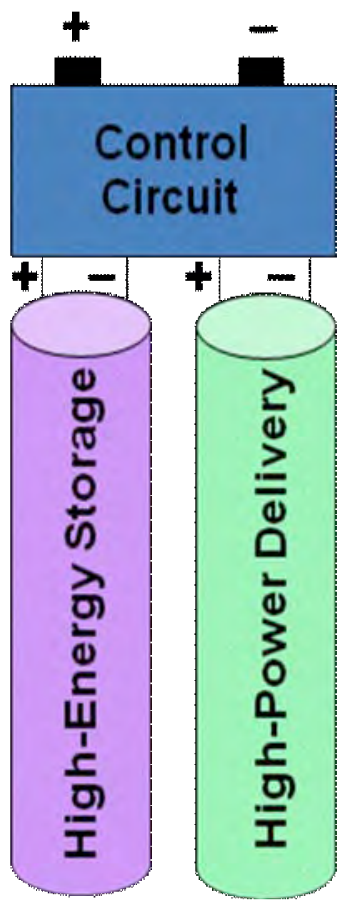

Figure 2. Block diagram showing the major components of the Nanotechnology-enabled Hybrid Power System. 


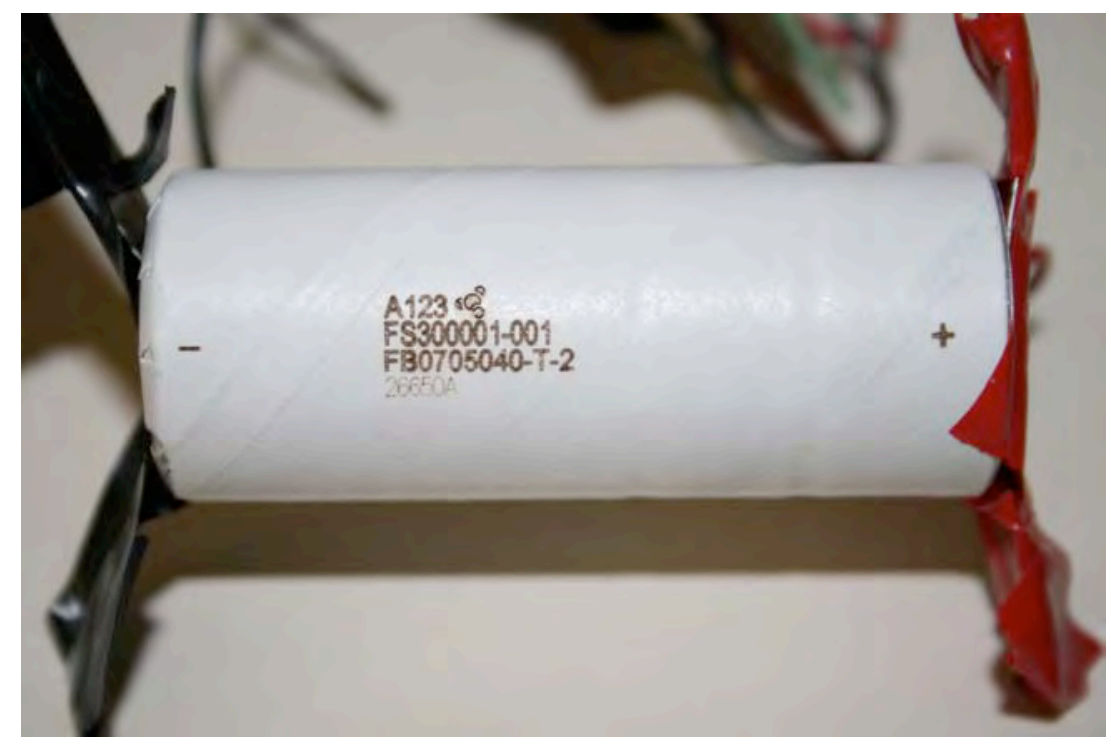

Figure 3. A123 Systems nanotechnology-enabled battery, with an $\mathrm{LiFeO}_{4}$ cathode, used as the high-energy storage component in the NHPS. This battery is approximately $6.5 \mathrm{~cm}$ long.

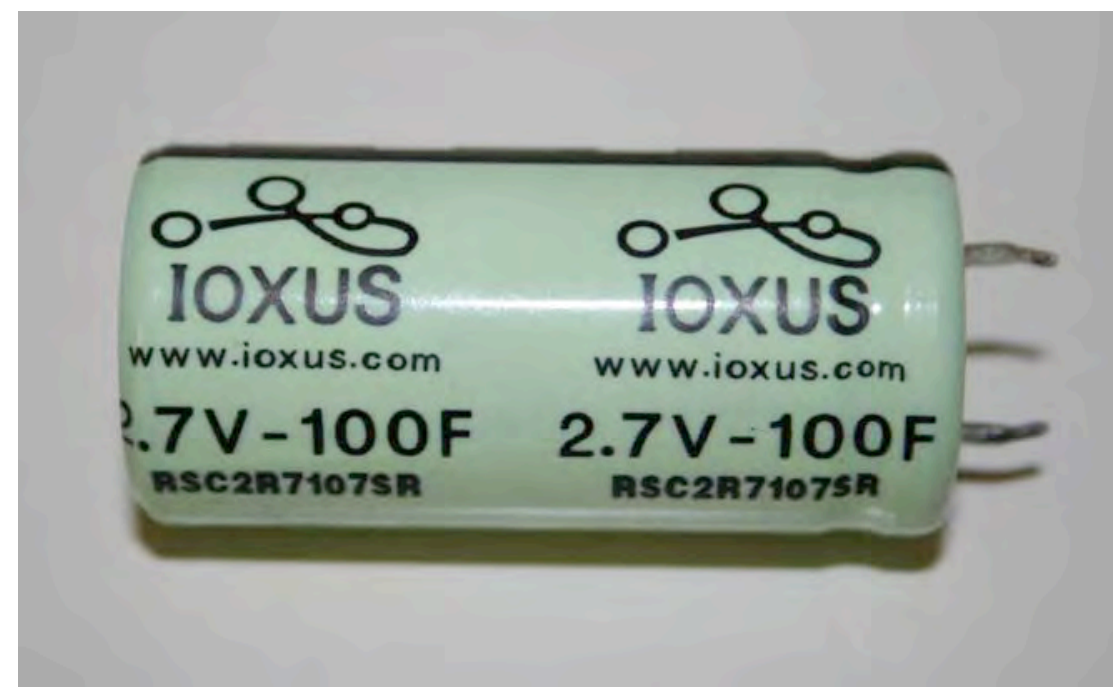

Figure 4. Ioxus nanotechnology enhanced supercapacitor used as the high-power delivery component in the NHPS. This supercapacitor is approximately $4.5 \mathrm{~cm}$ long. 
Descriptions of hybrid circuits that use a battery and a capacitor directly connected in parallel have been published previously [14]. However, there are deficiencies in such a simple configuration. One of its primary deficiencies is that the battery is still directly connected to the load, even under high current pulses. Because the battery and the supercapacitor are connected in parallel, the voltage across each element is the same. Under low load conditions this voltage equality is easy to maintain, with the capacitor supplying current to the load and the battery supplying an equal amount of charge to the capacitor. As the current draw is increased during high power spikes, the capacitor still will be able to supply current to the load and the battery will try to resupply current to the capacitor to compensate for the high rate of discharge demanded by the application. If the rate of recharge of the capacitor exceeds the rating of the battery, though, internal resistances will go up. This results in loss of efficiency and capacity, as well as eventual damage to the cell.

This deficiency can be ameliorated or eliminated through the use of a control circuit, as shown in Figure 5. This circuit uses a current sensor to monitor battery current. If the current exceeds the maximum level needed for efficient battery performance, a comparator is used to activate a switch and disconnect the battery from the load. With such a safeguard, the conditions under which the battery operates can be maintained in a region that produces highly efficient operation and long lifetime. The specific circuit components used to implement the control circuit for this work were chosen to minimize power consumption and promote overall system efficiency.

The three components described above--the $\mathrm{A} 123 \mathrm{LiFePO}_{4}$-based nanoenabled battery, the Ioxus nanoenabled supercapacitor, and our custom-designed control circuit--were assembled into a prototype hybrid power system according to the conceptual plan displayed in Figure 2 and the electrical schematic given in Figure 5. A photograph of the prototype is shown in Figure 6.

At this stage of the system's development, we have not attempted to optimize its performance per unit of weight or volume. For this initial laboratory prototype, the control circuit was assembled on a breadboard and, thus, had a relatively large area. We project, though, that a refined version of the entire control circuit, including the key giant magnetoresistive (GMR) current sensor, easily could be put on a chip having an area of only about $0.25 \mathrm{~cm}^{2}$. With the refined packaging possible as a result, an entire nanotechnology enabled hybrid portable power system with the same operating characteristics as the one built and tested in this work would have a total volume of approximately $60 \mathrm{~cm}^{3}$. 


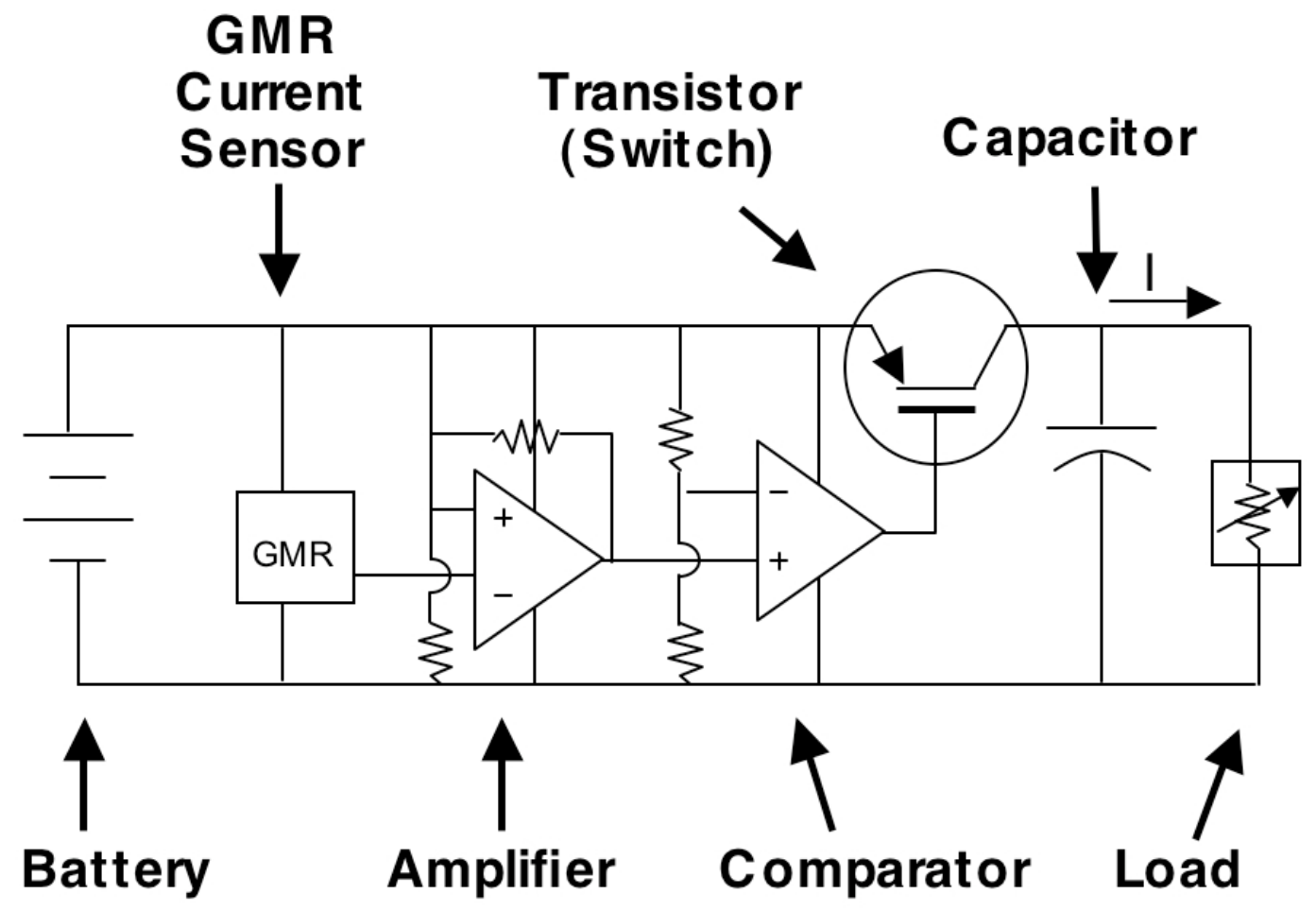

Figure 5. Control circuit for Nanotechnology-enabled Hybrid Power System, including the GMR current sensor. 


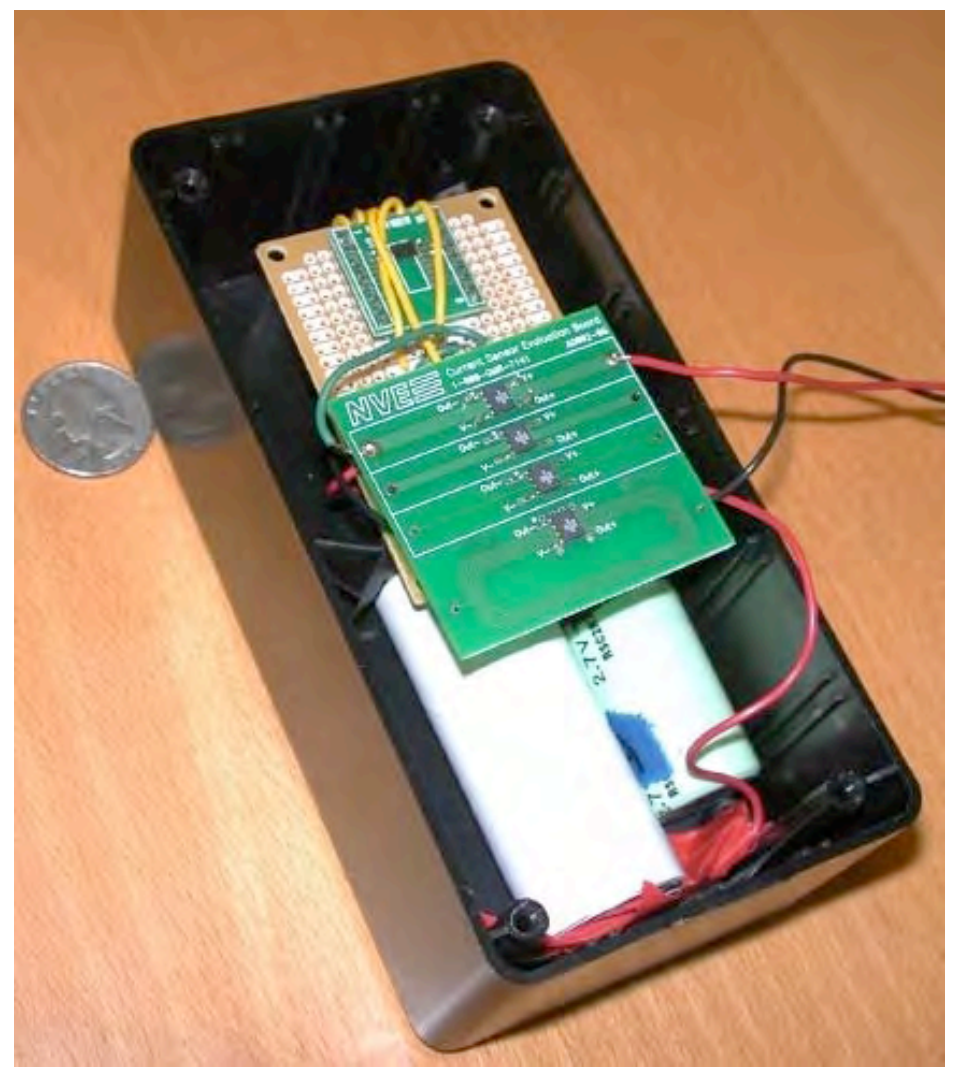

Figure 6. Initial laboratory prototype of nanotechnology-enabled portable power system that was assembled and tested in this work. A better packaged version of the system, with the control circuit breadboard replaced by an integrated circuit chip, would occupy only about $60 \mathrm{~cm}^{3}$. 


\subsection{Laboratory Results}

The NHPS prototype described in Section 2 was tested under a variety of conditions. The first test performed was cyclic voltammetry $(\mathrm{CV})$. This test uses a computer controlled bipotentiostat (Pine Research Instrumentation AFCBP1 and PineChem Voltammetry software) to sweep the potential of an electrochemical cell between defined limits and is used to characterize the electrochemical reactions occurring in the cell. See Figure 7. The CV plot for the battery alone is shown in Figure 8 and the plot for the supercapacitor alone is shown in Figure 9. From these plots, the specific energy and specific power can be calculated. The battery has a specific energy of $97 \mathrm{Wh} / \mathrm{kg}$ and a specific power of $702 \mathrm{~W} / \mathrm{kg}$, while the supercapacitor has a specific energy of $5 \mathrm{Wh} / \mathrm{kg}$ and a specific power of $18,000 \mathrm{~W} / \mathrm{kg}$. From these results, it is clear that the battery is more effective as an energy storage device, while the supercapacitor is more effective as a power delivery device.

The CV plot for the entire NHPS is shown in Figure 10. Using CV measurements, the NHPS was shown to produce $89 \mathrm{Wh} / \mathrm{kg}$ and $2663 \mathrm{~W} / \mathrm{kg}$. This specific energy (energy per unit mass) exceeds the specific energy of the supercapacitor by 1680 per cent, or approximately a factor of 17; and the specific power (power per unit mass) exceeds the specific power of the battery by 279 per cent, or approximately a factor of 3 .

As discussed above, the applications that benefit most from this type of NHPS are ones with low duty cycle and high power profiles. To test the system under such conditions, a computer controlled electronic load (BK precision 8510) was connected to the NHPS and programmed to simulate the power demands of a typical telecommunications system. The baseline power was simulated by a sequence of current demands averaging $267 \mathrm{~mA}$ over 30 seconds (200 mA for 10 seconds then $400 \mathrm{~mA}$ for 10 seconds then $200 \mathrm{~mA}$ for 10 seconds). The transmit/receive power was simulated by a 50 milli-second, 3 A current spike every 30 seconds. Results of the tests under these conditions are displayed in Figures 11, 12, and 13.

Figure 11 shows the performance of the supercapacitor alone in response to the electronic load. The blue curve shows that, due to its high power capability, the supercapacitor can follow the current demands of the load very well, even during the low impedance phases of the cycle. The red curve, however, shows the characteristic linear degradation in the supercapacitor voltage and very low capacity before a voltage threshold cutoff condition of $2 \mathrm{~V}$ is exceeded. From this data, the capacity of the supercapacitor under these load conditions can be calculated as $0.035 \mathrm{Wh}$.

Figure 12 shows the performance of the battery alone under load conditions similar to those described above. The current response of the battery, the blue curve, shows inconsistencies in pulse pattern. This is especially apparent in the variations in peak height and peak spacing. The cause of this variation is the lesser capability of the battery to deliver power. While the load is presenting a consistent impedance pattern, the battery is not able to supply enough power to match this load consistently. This indicates that the battery is being stressed beyond its high efficiency region and could experience degradation of its lifetime. The red voltage curve shows the flatter discharge curve characteristic of batteries. The battery reaches the $2 \mathrm{~V}$ threshold after a significantly larger number of cycles than the supercapacitor and has a capacity of $1.10 \mathrm{Wh}$ under these load conditions. 


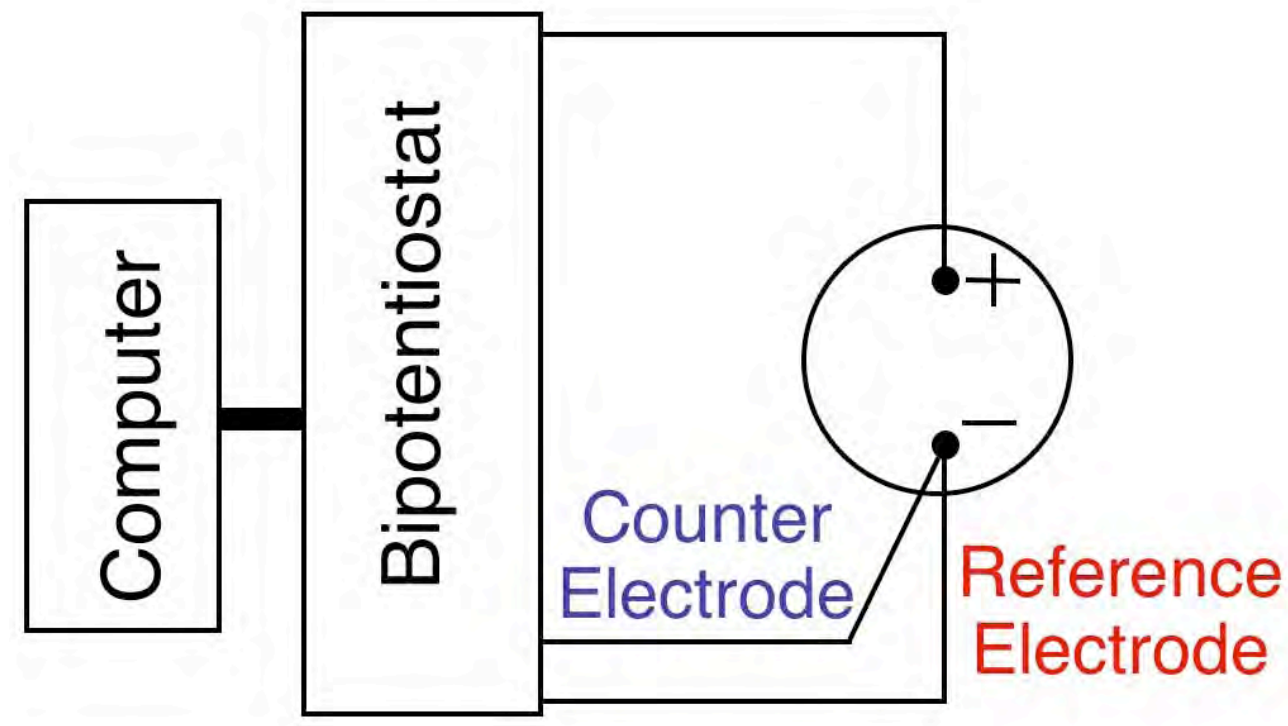

Figure 7. Schematic diagram of the experimental set-up used for bipotentiostat measurements. 


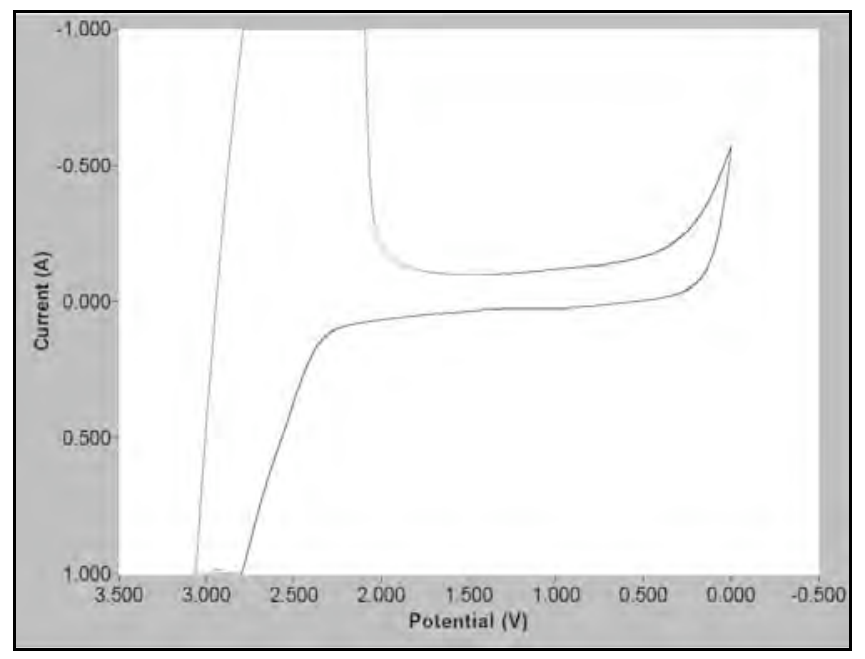

Figure 8. Cyclic Voltammetry (CV) plot for high-energy storage component (battery) of NHPS.

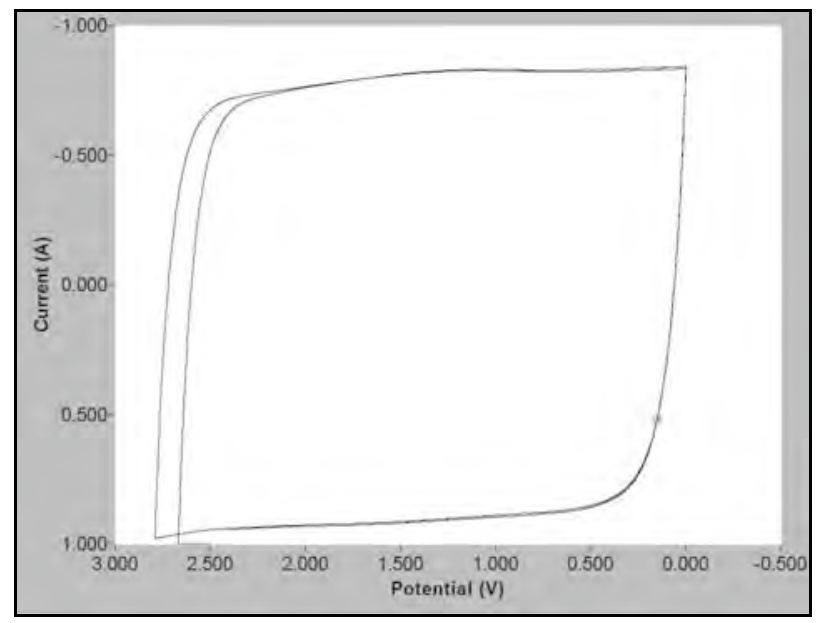

Figure 9. CV plot for high-power delivery component (supercapacitor) of NHPS.

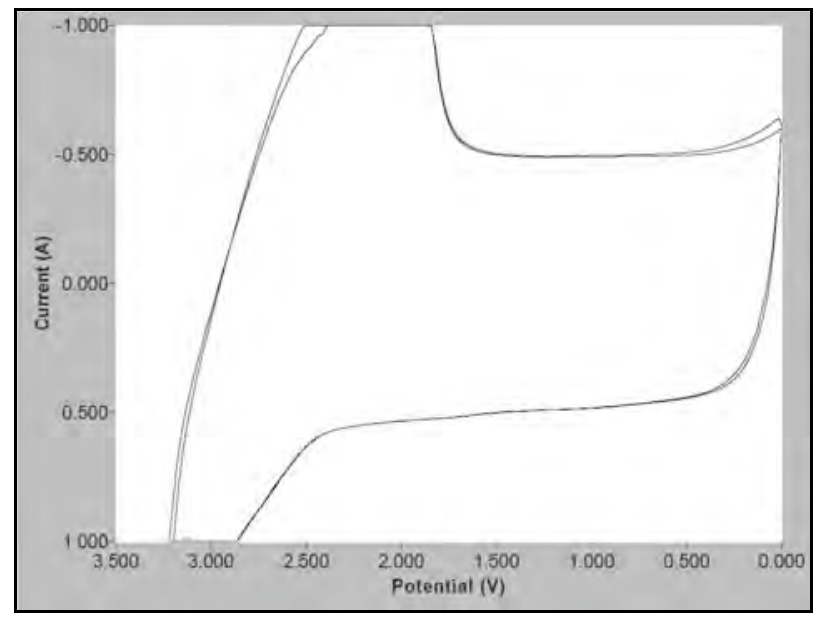

Figure 10. CV plot for entire NHPS. 


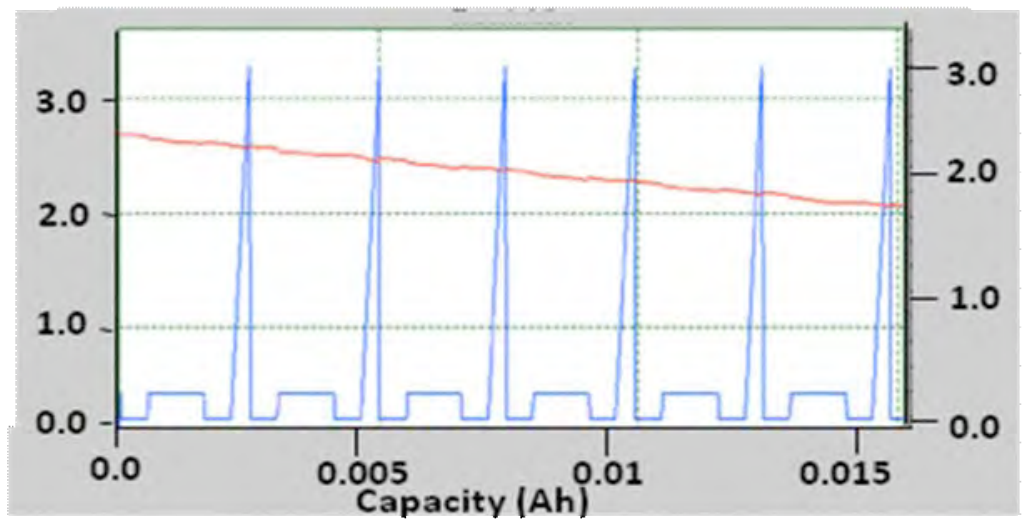

Figure 11. Supercapacitor discharge profile under simulated telecommunications load conditions. Blue curve shows supercapacitor current profile and red curve shows supercapacitor voltage profile.

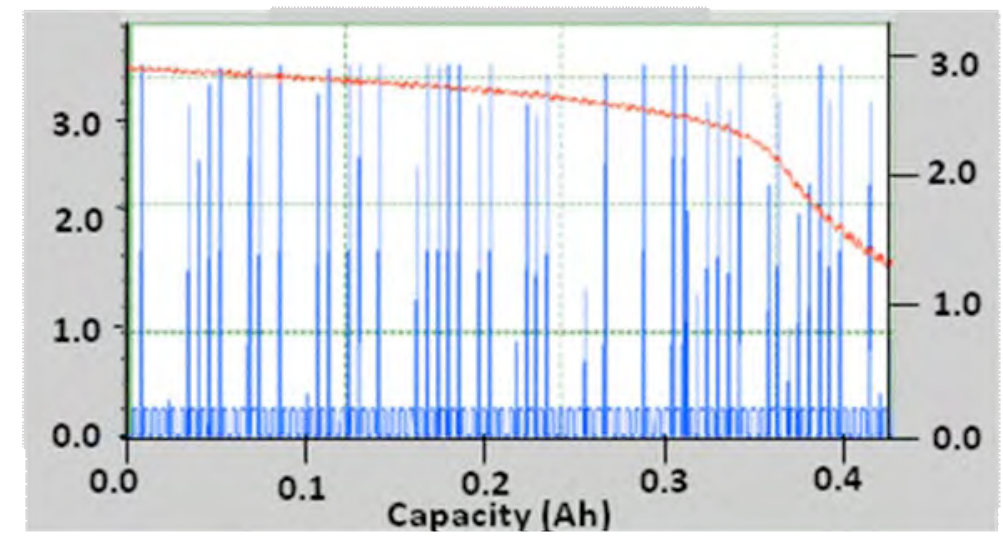

Figure 12. Battery discharge profile under simulated telecommunications load conditions. Blue curve shows battery current profile and red curve shows battery voltage profile.

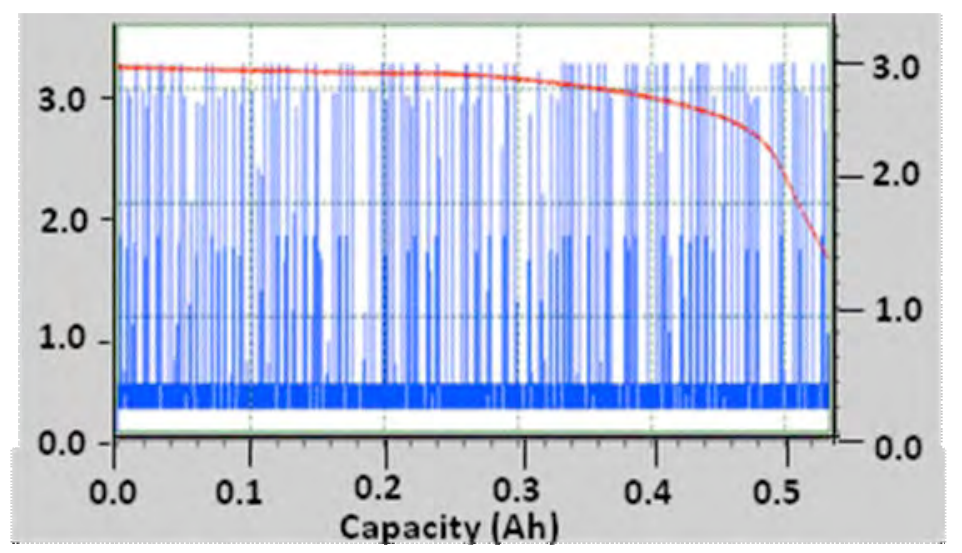

Figure 13. NHPS discharge profile under simulated telecommunications load conditions. Blue curve show NHPS current profile and red curve shows NHPS voltage profile. 
The performance of the NHPS under the same load conditions is shown in Figure 13. The current response of the NHPS is much more consistent than the current response of the battery alone, indicating the role of the supercapacitor in meeting the high power demands of the load and in protecting the battery from potentially damaging conditions. The red curve indicates that the capacity of the NHPS is excellent. The capacity calculated from this data is $1.47 \mathrm{Wh}$. This exceeds the capacity of the battery by 34 per cent and the combined capacity of the battery and supercapacitor by 30 per cent. 



\subsection{Summary and Conclusions}

A nanotechnology-enabled hybrid power system consisting of a nanotechnology-enabled Li-ion battery and a nanotechnology-enhanced supercapacitor, plus a dynamic power management circuit, has been designed, constructed, and tested. This system is designed to increase the operational domain beyond that achievable with either a battery or supercapacitor alone. The NHPS shows a 1680 per cent improvement in specific energy compared to the supercapacitor and a 279 per cent increase in specific power compared to the battery. Such a system is relatively inexpensive, and it is especially well suited to high power, low duty cycle applications, such as telecommunications systems or unattended ground sensors. When tested under conditions that emulate those likely to be experienced in these applications, the NHPS has a capacity that is 34 per cent greater than the battery and 30 per cent greater than the combined capacities of the battery and the supercapacitor.

This high level of performance, combined with the relative simplicity, light weight, and low cost of the prototype power system, shows the promise of the hybrid power system approach to enhance the performance and expand the design envelope of portable telecommunications and sensor systems. Further steps toward realizing this promise will include optimizing the form factor and performance of the NHPS for use in specific portable telecommunications systems of interest to the Government. 



\section{Acknowledgement}

The authors thank Dr. Jeffrey Poston, formerly with the MITRE Corporation and now with GCI, Inc., in Reston, Virginia, for valuable discussions that were of assistance in initiating the research and development described in this report.

\section{References}

[1] Sony Corp. News Releases 2009, Sony Corporation, [Online] August 11, 2009. [Cited: October 14, 2010.] www.sony.net/SonyInfo/News/Press/200908/09-083E/index.html

[2] Toshiba News Releases, Toshiba Corporation, [Online] March 29, 2005. [Cited: October 14, 2010.] www.toshiba.co.jp/about/press/2005_03/pr2901.htm

[3] H. Brandhorst and Z. Chen, Sixteenth Annual Battery Conference on Applications and Advances, pp. 153-156 (2001).

[4] L. Gao, R. Dougal and S. Liu, IEEE Transactions on Power Electronics, vol. 20(1), pp. 236-43 (2005).

[5] A. Leedy and R. Nelms, 37th Intersociety Energy Conversion Engineering Conference, pp. 1-6 (2002).

[6] J. Cao, A. Emadi, IEEE Vehicle Power and Propulsion Conference, pp. 941-6 (2009).

[7] D. Cheng, M. Wismer, 2nd IEEE Conference on Industrial Electronics and Applications, pp. 2913-2918 (2007).

[8] A123 Systems Technology, A123 Systems Inc. [Online] [Cited: October 14, 2010.], www.a123systems.com/a123/technology

[9] M. S. Halper and J. C. Ellenbogen, "Supercapacitors: A Brief Overview," Report No. MP 05W0000272, The MITRE Corporation, McLean, Virginia, March 2006.

[10] M. Wang, C. Wang, M. Chen, Y. Wang, Z. Shi, X. Du, T. Li and Z. Hu, New Carbon Materials, vol. 25, pp. 285-290 (2010).

[11] X. Li, C. Han, X. Chen, C. Shi, Microporous and Mesoporous Materials, vol. 131, pp. 303309 (2010).

[12] D. Pech, M. Brunet, H. Durou, P. Huang, V. Mochalin, Y. Gogotsi, P. Taberna and P. Simon, Nature Nanotechnology, vol. 5, pp. 651-654 (2010).

[13] P. Banerjee, I. Perez, L. Henn-Lecordier, S. Lee and B. Rubloff, Nature Nanotechnology, vol. 4, pp. 292-296 (2009).

[14] Z. Chen, 35th Intersociety Energy Conversion Engineering Conference and Exhibit, vol. 2, pp. $752-755$ (2000). 
